\title{
AS FRONTEIRAS IMAGINÁRIAS NA OBRA CAPITÃES DA AREIA DE JORGE AMADO.
}

\author{
Nikesara Luana \\ Rafaela de Sousa Trentini
}

RESUMO: Este trabalho abordará a questão das fronteiras imaginárias construídas na obra de Jorge Amado, Capitães da Areia. Ao longo da obra nota-se uma fronteira não explícita na cidade de Salvador, Bahia, entre a cidade alta, onde residiam os moradores de classes sociais mais abastadas, e na cidade baixa, onde residiam os moradores de poucas posses e mesmo os moradores de rua. Na obra os personagens principais são meninos de rua órfãos que não querem ir para orfanatos, e sim morar em bando em um píer na cidade baixa, e assim nota-se que estes personagens atravessam a fronteira entre a cidade baixa e a cidade alta duas vezes apenas, e quando o fazem são duramente repreendidos. O artigo focará então na questão da construção desta fronteira imaginária e como ela é exercida na obra.

PALAVRAS-CHAVES: fronteiras imaginárias; Jorge Amado; Capitães da Areia.

A criação de fronteiras simbólicas, o poder das autoridades e a relevância das leis na Bahia na obra de Jorge Amado, Capitães da Areia.

O seguinte artigo irá analisar a obra de Jorge Amado, Capitães da Areia, com o intuído de buscar compreender o modo com que o autor irá construir a sua concepção a respeito da cidade de Salvador. Como o autor irá delimitar as suas fronteiras simbólicas e como o autor irá distribuir a sociedade de acordo com estas fronteiras. Pretendemos também analisar como ocorre a aplicação dos meios de controle para os diferentes grupos sociais existentes na cidade construída por Jorge Amado.

Para podermos definir o que são as fronteiras simbólicas e como um autor, na descrição de determinadas cidades constrói estas fronteiras, utilizamos o historiador Robert Darnton com sua obra $O$ grande Massacre de Gatos. Na obra o autor inicia sua análise 
defendendo que um escritor, ao descrever a sua cidade-objeto irá inserir certa subjetividade e parcialidade na descrição. De certa maneira, o autor irá sempre expor a sua cidade de acordo com os valores contemporâneos a ele mesmo, bem como aos seus valores e crenças pessoais. Nas palavras de Darnton: "Como uma visão urbana pode estar carregada de emoções, valores e visão de mundo" ${ }^{1}$. Sendo assim as crenças do autor a respeito de sua visão de mundo estarão interligadas a sua análise e a sua delimitação da cidade que pretende ser descrita.

Para analisar estas questões e definir como era organizada a cidade a partir de pontos de vista literários, ou no caso especifico de um burguês, o autor irá utilizar como fonte a Description da cidade de Montpellier, escrita por um burguês o qual o nome não é revelado durante a obra, situada na França por volta de 1748. A partir desta Darnton irá traçar todo um panorama a respeito de como a cidade era vista através da classe burguesa, e como ela iria organizar o seu espaço urbano a partir de elementos diferenciadores entre as classes sociais presentes no período analisado.

Ao longo de todo o texto Darnton irá referenciar a Description. Um dos pontos principais, que podem nos trazer grandes contribuições para a análise é de como será descrita a Procissão religiosa ocorrida na cidade de Montpellier. Esta procissão, segundo a descrição será organizada a partir de vários elementos e classes, em primeiro viriam os integrantes do Primeiro Estado francês, ou seja, o clero, em segundo seria o Segundo Estado. E ai haveria já uma separação entre as hierarquias mais altas deste Segundo estado, e as mais baixas. Para tanto notamos que a riqueza, o status e o poder eram elementos diferenciadores sociais dentro de suas próprias camadas. Como cita Darnton:

\footnotetext{
${ }^{1}$ DARNTON, Robert. O grande massacre de gatos. Rio de Janeiro: Graal, 198, p. 143.
} 
Assim a riqueza, o status e o poder não andavam de braços dados num único código penal. Havia complexidades e contradições na comédia humana que desfilava na Description. ${ }^{2}$

O Terceiro Estado, em certa medida poderia participar da procissão, no entanto, de acordo com o seu status, deveria ou ficar a uma distância considerável dos primeiros estados, ou deveria apenas assistir a mesma. Nota-se, então, que em certa medida possuímos uma separação profundamente social entre os próprios grupos sociais franceses.

Tendo em vista o contexto com que esta descrição está ocorrendo, está próximo à Revolução Francesa, os burgueses, representantes do Terceiro Estado, já vinham reivindicando maiores direitos e participações nas questões urbanas, bem como reivindicavam status, querendo aproximar-se dos nobres. E isto irá acontecer de forma gradativa.

À medida que o status e o poder burguês iriam aumentando, assim aumentava também a distância entre o próprio Terceiro Estado, que iria segregando-se, tendo em vista o interesse dos burgueses em se contrapor aos grupos sociais com menor poder aquisitivo, ou ainda considerados rudes e miseráveis. Havia um interesse de distanciamento de operários.

A partir deste momento que começa a se notar um grande aumento da segregação dentro do espaço urbano. Agora com os ideais burgueses de contraposição as massas, vários elementos seriam pertinentes para uma diferenciação. Um dos exemplos seria a separação cultural dentro do Terceiro Estado, questões como a lingüística e a vestimenta seriam elementos diferenciadores. Com a separação cultural, também haveria uma separação geográfica, onde os grupos semelhantes iriam agrupar-se em torno de si mesmos, procurando uma distância daquele contrário as suas questões culturais e também econômicas. "A roupa será como código social em

${ }^{2}$ Idem, p. 159. 
Montpellier, como em todas as outras partes da Europa, no inicio dos tempos modernos" ${ }^{3}$.

Nota-se no espaço urbano, portanto, uma clara distinção dos locais de socialização, tendo os grupos semelhantes agregados de acordo com seus status e poderes aquisitivos. Sendo assim a cidade ficava organizada através de fronteiras que separavam as camadas umas das outras. Mas estas fronteiras não existiam de fato, não havia algo sólido que separassem as pessoas no espaço urbano, estas fronteiras eram meramente imaginadas e simbólicas de acordo com Darnton.

Estas fronteiras seriam defendidas pelos grupos de maior status. Principalmente quando havia a penetração de indivíduos exteriores ao espaço que seria reservado a um determinado grupo social. Como por exemplo, quando havia a presença de um miserável em um bairro que era considerado burguês. Essa interação era considerada perturbadora para os indivíduos de classes maiores. Darnton afirma que essas interações eram constantes, e que não se pode pensar, mesmo que existam as fronteiras imaginadas, que não havia um intenso movimento de ultrapassagem destas fronteiras.

Mas seria um equivoco sugerir que a sociedade urbana segrega-se em esferas culturais separadas, ou que a consciência do nosso autor, embora burguesa, permaneça imperturbável. Ele se preocupava, e essencialmente com o problema da ultrapassagem de fronteiras. ${ }^{4}$

É perceptível, portanto uma intensa preocupação com a inviolabilidade destas fronteiras imaginárias, pois elas constituíam em uma ameaça a ordem social. Para tanto era necessária uma intensa vigilância e também punições para aqueles que descumprissem a "regra” da não ultrapassagem. Esta regra não era uma lei de fato, constituía-se mais em uma regra social, que vinha sendo agregada aos ideais urbanos. E a maneira de separar os grupos seria a represália dos mais fracos.

\footnotetext{
${ }^{3}$ Idem, p. 172.

${ }^{4}$ Idem, p. 175.
} 
Mas as autoridades eram demasiado indulgentes. Elas exigiam prova antes de determinar o castigo, e nunca puniam com severidade suficiente, quando a única maneira de conviver com o 'Terceiro Estado' seria mantêlo em seu lugar. ${ }^{5}$

Tendo analisado toda a questão exposta por Robert Darnton podemos nos remeter a partir deste referencial, a obra Capitães $d a$ Areia de Jorge Amado. Nesta obra o autor irá demonstrar todo o panorama urbano e social da cidade de Salvador na Bahia, tendo como seus principais personagens, meninos órfãos que vivem em um Píer abandonado frente a uma praia. Estes meninos vivem em bandos, e recusam-se a se encaminharem a instituições de caridade ou a orfanatos, preferindo viver em um mundo suburbano e de condições insalubres, vivendo de atividades ilícitas como o roubo de pequenas mercadorias ou ainda de comida.

Na obra notamos, da mesma forma com que na Description, uma intensa segregação entre os grupos sociais. A cidade que Jorge Amado irá construir possui duas regiões bastante distintas. A cidade alta, e a cidade baixa. Na primeira há uma agregação de indivíduos de grande ou médio poder aquisitivo, entre outros elementos de agregação cultural. Na cidade baixa viviam indivíduos, dentre eles os personagens de Amado, que eram considerados marginalizados e possuíam baixo poder aquisitivo.

Esta diferenciação entre cidade alta e baixa se dá também na questão do relevo da região, mas principalmente trata-se de uma clara referencia a fronteira imaginada descrita por Robert Darnton. Há uma pequena integração entre os indivíduos das duas partes da cidade, e quando esta fronteira era violada, os olhares para os determinados personagens eram de desconfiança e de perturbação, que também fora referenciado por Darnton.

$\mathrm{Na}$ obra de Amado, podemos notar que há uma pequena integração da cidade baixa com a cidade alta. Os personagens que amado nos apresenta apenas ultrapassam as fronteiras simbólicas por

${ }^{5}$ Idem, p. 171. 
apenas duas vezes. Quando eles o fazem as autoridades ficam atentas para com as suas atitudes. Pois como foi notado na Description e reforçado por Darnton, havia a tentativa de manter afastados estes elementos considerados marginalizados.

Amado então descreverá a cidade de acordo com a sua subjetividade, demonstrando Salvador de acordo com seus princípios e valores do início do século XX, bem como também expondo os problemas que existiam na cidade. Em relação às fronteiras simbólicas, o autor delimitará de acordo com os grupos sociais e também pelo poder aquisitivo.

Para poder demonstrar melhor esta questão, fizemos uma breve análise de alguns capítulos da obra de Amado que são pertinentes as questões tratadas no trabalho. Neles poderemos observar como estas questões aparecem.

\section{Capítulo: Família}

$1^{\circ}$ rompimento de barreira dos capitães

Nessa parte da obra, aparece claramente um dos golpes dos capitães, inserir um de seus na cidade alta, para que ele (o escolhido é sempre sempernas, pois é coxo e seu defeito físico é digno de pena) se fixe em uma residência e descubra a localização de tudo que tenha valor. Sem-pernas nessa parte do livro é adotado pela família não como um menino de recados ou para compras, não é um empregado mais é acolhido como filho, e até questiona permanecer lá e abandonar o grupo, não é o que acontece, mantém sua lealdade aos capitães e abandona a casa, abandona a cidadealta, o conforto e a dignidade em prol de liberdade e lealdade. ${ }^{6}$

Outra questão que podemos apresentar se trata a respeito dos mecanismos de controle empregados nas diferentes regiões da sociedade. Quando se trata de algum tipo de repressão na Cidade Alta em relação aos seus moradores, trata-se de uma repressão branda, em se tratando da análise da obra. No entanto, ainda na Cidade Alta, quando algum indivíduo exterior a ela, ou seja, da Cidade Baixa está

${ }^{6}$ AMADO, Jorge. Capitães da Areia. São Paulo: Círculo do Livro, s/d, pp. 106120. 
presente na primeira, a repressão deve ser mais severa, visto ainda a frase de Darnton que estas classes deveriam ficar em seu lugar. Quando entravam na cidade alta, eram pré-julgados em relação ao seu caráter e as suas atitudes. Na cidade baixa observamos uma falta de mecanismos de controle das autoridades na obra. Uma hipótese era de que esta região de certa forma era negligenciada pelas autoridades em algumas questões, como a questão do furto cometido pelos meninos órfãos, muitas vezes eram feitas vistas grossas e não havia uma efetividade quanto à represália destas ações.

Há diferenças também em relação a mecanismos de controle referentes à saúde pública e ao trato oferecido aos diferentes grupos sociais de ambas as regiões da cidade de salvador. Podemos citar outra análise de capítulo que seria pertinente apresentar.

$2^{\circ}$ rompimento

Alastrim

Aqui a discussão se refere ao surto de varíola que atinge salvador, no entanto nota-se perfeitamente as barreiras pois os mecanismos de controle da doença são diferentes pois para a cidade alta existe a vacina, lá eles se protegem, quem fica doente então é a população pobre da cidade baixa que não conhece ou não tem condições de tomar a vacina, então tem-se um decreto obrigando a denuncia de todos os casos de varíola a serem levados para o lazareto (uma espécie de hospital de quarentena) de onde é praticamente impossível voltar vivo. Boa-vida é um dos capitães que pega varíola, por conta própria e para não contagiar os demais vai sozinho ao lazareto, incrivelmente volta vivo. ${ }^{7}$

Para a continuidade da análise a respeito da obra, seria interessante apresentarmos como a idéia de Jorge Amado a respeito do Nordeste e como ele foi construído pelo autor pode contribuir para a compreensão de como ele delimita a sua obra.

De acordo com Durval Muniz de Albuquerque Junior, o nordeste brasileiro como o conhecemos passou a existir somente

${ }^{7}$ Idem, pp. 129-145. 
depois de escritores como Gilberto Freyre, Ariano Suassuna e Jorge Amado, isso porque antes, toda essa porção que corresponde ao nordeste era tida como porção norte.

Ainda segundo o autor, o nordeste foi construído cultural e socialmente pois não existem barreiras físicas que distinguem o norte do nordeste, mas a sua cultura aqui utilizando o significa mais amplo da palavra o tornam único e diferente, essa face porém não era reconhecida até que essa sua imagem fosse propagada através da literatura.

Para Albuquerque é a literatura que promove a formação de uma delimitação imagética, porém muito clara entre as porções geográficas da nação, sendo que na literatura isso pode ser observado com correntes de pensamento diferentes. Sendo o nordeste o espaço da saudade, que o tomam por um tipo de lugar edílico que preserva uma mística preservação da pureza do Brasil, ou como espaço de denuncia, denúncia da fome, miséria e descaso. Que é onde exatamente se insere a obra de Jorge Amado, já que seus temas sempre demonstram o sertanejo como àquele que luta constantemente por sua vida sem perder sua alegria e seu jeito preguiçoso, despreocupado ao mesmo que é trabalhador e valente.

A respeito dos mecanismos de controle e sua eficácia na Bahia, através do artigo "de olho no canto" de João José Reis fica claro que os mecanismos de controle são muito mais fortes na cidade baixa de Salvador do que na cidade alta, pois o grande medo da policia ou de qualquer órgão que exerça os mecanismos de controle é que qualquer ameaça chegue à cidade alta.

Os cantos que são os grupos de trabalho etnicamente organizados, sofrem constante controle por parte das autoridades baianas, pois quando se deu a revolta dos malês vários dos que trabalhavam nos cantos contribuíram para ela. Em paralelo ao estudo da obra capitães de areia, pode-se utilizar o artigo de Reis no que tange a idéia da existência de limites, fronteiras para a eficácia, ou melhor, para o menor ou maior grau de aplicação dessa lei, Reis especifica que as leis de controle das atividades dos cantos destinam- 
se quase exclusivamente aos cantos situados na cidade-baixa perto da região portuária, o que leva a questão de que provavelmente os mesmos mecanismos não se aplicam a cantos situados em outras regiões, da mesma forma, Jorge Amado em Capitães da Areia mostra que as autoridades baianas estão em constante vigília da cidade-baixa pois mesmo procurando manter-se alerta ainda assim, a cidade alta não fica totalmente protegida de crimes.

A obra de Reis faz referencia não apenas ao fato de que existia uma legislação severa aos cantos da cidade-baixa de Salvador como também que existia a possibilidade de distinção da forma como essa legislação era composta, mais severa dentro do simbólico limite dos portos da cidade-baixa, mais branda nas freguesias da cidade alta.

$\mathrm{O}$ artigo de Reis demonstra que existiam fronteiras imaginárias onde a atuação da policia era mais ou menos forte na cidade da Bahia, a cidade de Salvador, dividia simbolicamente em cidade alta e cidade baixa tinha mecanismos de controle da população diferenciados, sendo os mais agressivos sempre para a cidade baixa, os cantos de trabalho que sofreram constante mudança em sua regulamentação eram exclusivamente da cidade baixa de Salvador, e era considerado necessário seu maior controle porque as autoridades estavam convencidas de presença de pessoas desses cantos na revolta dos malês, assim sendo, sim existem barreiras imaginárias dividindo a cidade de Salvador, e mais que isso, a policia e o Estado criam e tentam ao máximo aplicar medidas de controle sob essa população especifica tentando não correr o risco dessa população perigosa subir as ladeiras rumo a cidade alta de Salvador.

A título de ilustrar as fronteiras simbólicas de salvador e a pratica e eficácias dos mecanismos de controle, seguem trechos referenciados ao livro Capitães da Areia: 
Capitulo: Filha de bexiguento ${ }^{8}$

A discussão desse capitulo mostra exatamente a barreira social imaginária mas nem por isso menos presente, já que o capitulo vem a tratar de que Dora, personagem feminina que andará com os capitães ao perder a mãe, desce o morro para a cidade alta a procura de emprego, obviamente não consegue, pois ela é filha de pais que morreram de varíola, assim Dora é chamada ao trapiche dos capitães onde torna-se a única fêmea do bando. ${ }^{9}$

Podemos ainda demonstrar outra questão que se refere à questão da aplicação dos mecanismos de controle exercidos pelas autoridades baianas que são demonstrados na obra de Jorge Amado:

\section{Capitulo: reformatório e orfanato}

Esses capítulos tratam da eficácia dos mecanismos de controle criminal baiano, quando em uma tentativa frustrada de um assalto o grupo é pego, ainda assim o líder Pedro bala arma uma confusão e livra diversos deles. Menos Dora e a si próprio, então Pedro é mandado pro reformatório onde é torturado e sofre por diversos dias até fugir. Dora é mandada ao orfanato, onde não sofre as torturas que Pedro sofre, mas as isolações a tornam apática e triste, e de onde sai doente, depois morre em função dessa doença. ( o que leva a crer que apesar de não sofrer torturas é possível que a salubridade do local seja questionada).

Por fim, no final do livro, Pedro Bala, passa a ser um sindicalista convicto e a lutar pelas causas sociais (o comunismo e socialismo aparece na figura de João de Adão claramente um socialista grevistas residente das docas). ${ }^{10}$

A título de especificidade da obra Capitães da Areia, ser o escolhido, seria a principio pelas figuras malandras, depois surgiu a análise das fronteiras e eficácia e existência de mecanismos de controle na Bahia de Jorge amado, sobre o autor e sua obra, Zélia Gattai Amado em "Um baiano romântico e sensual", conta que Capitães da Areia foi escrito em exílio, justamente pelas idéias

${ }^{8}$ Bexiga é como a varíola é chamada; alastrim quando é varíola branca, forma branda similar ao sarampo.

${ }^{9}$ Idem, pp. 151-160.

${ }^{10}$ Idem, pp. 177-195. 
socialistas de Jorge Amado, conta também que a obra foi rejeitada na Bahia pelo seu conteúdo rebelde, chegando mesmo a ser queimada em praça pública, chega-se a conclusão de que o livro chegou ao Brasil juntamente com o combate as forças sindicais, e que sua recusa deveu-se a seu caráter de denuncia principalmente por Pedro Bala, líder dos meninos abandonados ter-se ao fim da obra tornar-se líder sindical e conhecido no sertão por isso, não bastasse a afirmação final da obra de que Pedro bala ainda que procurado teria pouso e seria acobertado em qualquer casa de doqueiro e ou operário já que lutava por justiça e igualdade de direitos.

Podemos concluir que as fronteiras simbólicas de fato existem, não somente na Description, ou na obra de Amado, mas também podemos notar estas barreiras ainda nas cidades contemporâneas. As fronteiras simbólicas estão relacionadas ao mundo urbano devido a grande diversidade nela contida. Em relação a obra de Amado os capitães da areia quebram as barreiras simbólicas existentes diversas vezes para seus assaltos e pequenos furtos, porém somente em situações extremas de riscos ou possibilidades de altos ganhos sua inserção é profunda nesse universo, até porque quando dentro da cidade alta, são sempre vistos com desconfiança e tratados de maneira desrespeitosa. As leis e sua efetividade existem tanto em uma porção quanto na outra, porém fica claro que na cidade alta ela é mecanismo de proteção dos ricos, enquanto que na cidade baixa ela é violenta e abusiva para que a suposta marginalidade existente não suba as ladeiras da urbe.

Amado, portanto constrói a sua análise a partir de fronteiras simbólicas de todos os tipos, culturais, socioeconômicas. Procura criticar esta questão da diferenciação entre as camadas sociais heroificando os seus personagens, sendo assim, procura diminuir esta questão da impossibilidade da ultrapassagem destas fronteiras. 


\section{BIBLIOGRAFIA}

AMADO, Jorge. Capitães da Areia. Salvador: FCJA, 2004.

. Capitães da Areia. Rio de Janeiro: Record, 1995.

AMADO, Zélia Gattai. Jorge Amado, um baiano romântico e sensual. Três relatos de amor: Zélia Gattai Amado, João Jorge Amado, Paloma Jorge Amado. Rio de Janeiro/São Paulo: Editora Record, 2002.

DARNTON, Robert. O Grande Massacre de Gatos e outros episódios da história cultural francesa. Rio de Janeiro: Graal, 1986.

REIS, João José. De olho no canto: trabalho de uma rua da Bahia na véspera da abolição. Revista Afro-Ásia, $\mathrm{n}^{\circ} 24$. Universidade Federal da Bahia. Bahia, 2000. 